\title{
Integration of hydrodynamics into a statistical model on the spread of pancreas disease (PD) in salmon farming
}

\author{
H. Viljugrein ${ }^{1,2}$, A. Staalstrøm ${ }^{3}$, J. Molvær ${ }^{3}$, H. A. Urke ${ }^{3}$, P. A. Jansen ${ }^{1, *}$ \\ ${ }^{1}$ National Veterinary Institute, PO Box 750 Sentrum, 0106 Oslo, Norway \\ ${ }^{2}$ Centre for Evolutionary and Ecological Synthesis (CEES), Department of Biology, University of Oslo, PO Box 1066 Blindern, \\ 0316 Oslo, Norway \\ ${ }^{3}$ Norwegian Institute for Water Research, Gaustadalléen 21, 0349 Oslo, Norway
}

\begin{abstract}
Pancreas disease (PD) is an emerging disease in salmon farming caused by the salmonid alphavirus (SAV). SAV is evidently spread horizontally between neighbouring salmon farms, but whether such transmission occurs by passive drift in the water current or via fomites is not known. We tested whether hydrodynamic modelling contributes to explain the spread of PD, in which case SAV is likely to spread by passive drift. We present a simple logistic regression model that accounts for the effect of PD in the neighbourhood on the probability of acquiring PD in cohorts of farmed salmonids from an area on the west coast of Norway between 2005 and 2008. For a given cohort, we calculated infection pressure (IP) based on Euclidean distance, seaway distance or estimated water contact to sites with PD, and compared the amount of variance explained in the regression model by the different variants of $I P$. Water contact between a discharging farm site and a receiving site was calculated by simulating particle discharge using a hydrodynamic model. IP estimated by water contact was the best predictor of PD cases and controls in the model, which performed significantly better than $I P$ estimated by seaway distance or Euclidean distance. Since the spread of PD in the study area was best explained by modelled water velocity, we conclude that PD is likely to be spread by passive drift of SAV in the water current.
\end{abstract}

KEY WORDS: Salmonid alphavirus $\cdot$ Transmission $\cdot$ Hydrodynamics $\cdot$ Infection pressure

\section{INTRODUCTION}

Pancreas disease (PD) is an emerging disease in salmon farming caused by the salmonid alphavirus (SAV; Weston et al. 1999). The numbers of outbreaks of PD in Norway have increased markedly in recent years, and the disease is among the most significant diseases in salmon farming (Fringuelli et al. 2008, Kristoffersen et al. 2009). Large-scale studies of factors associated with the risk of contracting PD in farmed salmonids have found that the single most important factor is the infectious status of proximate farms, suggesting horizontal spread of SAV between neighbouring farms (Kristoffersen et al. 2009). Phylogenetic stud- ies of SAV from clusters of PD outbreaks in Scotland and Ireland also support local farm to farm transmission (Fringuelli et al. 2008). Experimental studies of SAV survival in seawater suggest that passive spread of the virus between fish farms in the water current is possible (Graham et al. 2007). However, whether SAV is transmitted between farms directly through passive drift in the water or indirectly via fomites is not known. It has also been suggested that salmon lice Lepeophtheirus salmonis Krøyer, 1837 may act as vectors for SAV transmission and the spread of PD (Rodger \& Mitchell 2007, Petterson et al. 2009).

The main task of the present study was to test whether hydrodynamic modelling contributes to ex- 
plain the spread of $\mathrm{PD}$, in which case SAV is likely to be transmitted between fish farms through passive drift in the water current. One complicating factor in this task is the timeframe of events related to the infection processes versus the hydrodynamics. The data available for studying the spread of PD consist of the time and location of recorded outbreaks of the disease. The time delay between an infection event on a given site and the subsequent recording of a disease outbreak, or the actual distribution of the infectious agent SAV over time, are not known. In comparison, coastal waters are highly dynamic and currents that potentially may spread SAV between sites are constantly affected by winds, tides, fresh water discharge and other factors. Hence, rather coarse simplifications of both hydrodynamic processes and the dynamics of SAV infection and transmission are necessary in order to model the potential spread of SAV directly through passive drift in the water current. However, simple transparent models may be useful in aiding decision making aiming to control or prevent disease emergencies (Murray 2008). Detailed hydrodynamic models are complex, but more or less simplified versions, and more complex particle tracking models, have been used extensively to assess the spread of salmon lice from salmon farms as well as the spread of viral diseases in aquaculture (Murray et al. 2005, Stucchi et al. 2005, Amundrud \& Murray 2009). Tidal currents have also been shown to affect the spread of infectious salmon anaemia (ISA) in the Quoddy region of Atlantic USA and Canada (Gustafson et al. 2007). Simple tidal models were used to design a control regime that was used to eradicate ISA from Scotland (Stagg 2003).

Here we present a simple logistic regression model that accounts for the effect of neighbourhood PD status on the probability of acquiring PD in cohorts of farmed salmonids from a study area on the west coast of Norway between 2005 and 2008. For a given cohort, neighbourhood infectious status is expressed as a time varying exposure to infection from proximate farm sites where the fish are undergoing outbreaks of PD. This exposure we term infection pressure $(I P$; Kristoffersen et al. 2009). We calculated different variants of $I P$ based on Euclidean distance, seaway distance or estimated water contact to PD outbreak sites, and compared the amount of variance explained in the regression model by the different variants of $I P$. To calculate our estimate of water contact between farm sites, we used a 3-dimensional hydrodynamic model covering the study area. The calculations rely on particle discharge modelling from each of the farm sites over a modelled period of $1 \mathrm{wk}$. Our estimate of water contact between a discharging site and a given receiving site was based on the time from particle discharge to when a concentration of particles above the background level was attained on the receiving site, and the total particle concentration registered on the receiving site over the modelled week. We tested whether IP calculated on the basis of water contact is a significantly better predictor of acquiring PD in the study cohorts than other variants of $I P$. If so, this would suggest that PD is spread by passive drift in the water current.

\section{MATERIALS AND METHODS}

Hydrodynamic modelling. The Regional Ocean Modelling System (ROMS) with a horizontal resolution of $150 \mathrm{~m}$ was used for hydrodynamic modelling (Haidvogel et al. 2008). The vertical coordinate is terrainfollowing, and the model had 20 layers, with thickness around $1 \mathrm{~m}$ near the surface and between 1 and $8 \mathrm{~m}$ near the bottom (for water depths of 20 and $100 \mathrm{~m}$, respectively). Water current, sea level, salinity and temperature were calculated for each grid cell and water layer. The model can also calculate concentrations of discharged substances with neutral buoyancy.

The model was driven by the coastal current, the most important semidiurnal (M2) and diurnal tide (K1), freshwater inflow and wind. The starting conditions for the model were entered from a larger scale ocean model of the Norwegian coast with $4 \mathrm{~km}$ horizontal resolution (MI-POM) that is run by the Norwegian Meteorological Institute (http://met.no/English/R+D_ Activities/Oceanography/Numerical_ocean-models/). The coastal current was included in the MI-POM model, and water current, sea level, salinity, temperature and tide were specified as boundary conditions at the edges of the model area. The freshwater inflow was specified as point sources, and the wind was specified in each grid cell inside the model area.

The ROMS model was set up for an area of $2625 \mathrm{~km}^{2}$ in Sogn and Fjordane County. Within the area, there were 25 marine sites that farmed salmonids at some point in time during the study period, and 1 processing plant with holding pens for pre-slaughter salmonids (Fig. 1). The model was run with $5 \mathrm{~m} \mathrm{~s}^{-1}$ wind from NW, which according to wind measurements from Florø Airport (Fig. 1) is typical for the area. The total freshwater inflow in the model was kept constant at $343 \mathrm{~m}^{3} \mathrm{~s}^{-1}$. This roughly corresponds to the annual mean inflow of fresh water in the area (http://arcus. nve.no/website/nve).

In the initial phase of the set up of the ROMS model, the model calculations were compared to current measurements from 22 sites (Staalstrøm 2009). The results showed good agreement in both current direction and speed in the surface layer ( 0 to $5 \mathrm{~m}$ ), in the intermediate layer ( 5 to $20 \mathrm{~m}$ ) and below $20 \mathrm{~m}$. Most of the sites were located in the central parts of the study area 




Fig. 1. Study area. Geographic locations of farms hosting case and control cohorts, cohorts only contributing with infection pressure (IP farms), farms from where cohorts were relocated, current measurement instruments and a processing plant are indicated by symbols (see key). Farm sites are indexed according to Tables $2 \& 3$

(Fig. 1). Only 1 site was located in the southern part. The current measurements were carried out on the various farms between 2002 and 2006 in periods of typically 3 to $4 \mathrm{wk}$. Most of the sites were located close to land, and in order to further validate the ROMS model, current direction and velocity were measured in 4 positions (total depths: 30 to $50 \mathrm{~m}$ ) during a $40 \mathrm{~d}$ period in April to May 2008 (Fig. 1, Table 1). Measurements were taken at a depth of roughly $10 \mathrm{~m}$. This depth was chosen to avoid conflicts with ship traffic.

Water contact between the marine farm sites in the study area was studied by simulating particle discharge at time $t_{0}$ from the sites, and then modelling the particle concentration in the area over $1 \mathrm{wk}$. One week corresponds roughly to $t_{1 / 2}$ values for SAV survival in non-sterile seawater at temperatures around $10^{\circ} \mathrm{C}$ (Graham et al. 2007). The concentration of particles in the top water layer covering receiving sites was monitored during the $1 \mathrm{wk}$ model period. Water contact in the direction of a discharging site $j$ to a receiving site $i$ was estimated as:

$$
W C_{i j}=38+10 \ln \left(\frac{T}{A}\right)
$$

where $W C_{i j}$ is relative water contact (no dimension), $T$ is the time (h) from discharge to when the concentration of discharge substance is above the background level at the receiving site, and $A$ is the area under the concentration curve. The function is constructed such that low values of response time $(T)$ and high values for concentration $(A)$ yield low values for the water contact parameter and indicate high degrees of water contact between sites. The logarithmic scale was used to improve the assumption of a linear association on the logit scale. Parameters were scaled such that water contact values are comparable to physical distances. A cross-tabulation matrix of $W C_{i j}$ including only farm sites with a PD record as discharging sites is given in Table 2 .

To test the sensitivity of wind direction and the timing of the substance discharge in the model, 2 additional cross-tabulation matrices of $W C_{i j}$ were calculated (not shown): (1) the wind was changed to SW $\left(5 \mathrm{~m} \mathrm{~s}^{-1}\right)$; (2) timing of the substance discharge was changed from $t_{0}$ to $t_{6}(\mathrm{~h})$, corresponding approximately to a $180^{\circ}$ phase shift in the tidal current.

Fish cohorts, case and control data. In Norway, operators of marine sites farming Atlantic salmon Salmo salar L. and rainbow trout Oncorhynchus mykiss (Walbaum) are required to report key production statistics to responsible authorities on a monthly basis. These statistics are linked to a farm site identity which is geo-referenced in the Aquaculture register of The Directorate for Fisheries (http://www.fiskeridir.no/fiskeridir/akvakultur/ registre). From the production statistics data, a total of 32 cohorts of salmonids that were initiated and terminated in the period from January 2005 to July 2008 were identified and entered in the study (Table 3). Although 2 of the PD cohorts were not terminated by July 2008, they were included in the study because of their impact on infection pressure. The period from initiation to termination of a cohort covered the whole marine grow-out period for the cohorts. Cohort biomasses and

Table 1. Geographical coordinates, measurement period and specifications for the instruments used for current measurements at 4 stations (see Fig. 1) in the study area

\begin{tabular}{|c|c|c|c|}
\hline Station & Position & Measurement period (2008) & Instrument \\
\hline $\mathrm{C} 1$ & $61^{\circ} 37.524^{\prime} \mathrm{N}, 4^{\circ} 56.209^{\prime} \mathrm{E}$ & 17 Apr-26 May & AADI RCM11 \\
\hline $\mathrm{C} 2$ & $61^{\circ} 33.804^{\prime} \mathrm{N}, 5^{\circ} 01.661^{\prime} \mathrm{E}$ & 17 Apr-26 May & AADI RCM11 \\
\hline C3 & $61^{\circ} 29.135^{\prime} \mathrm{N}, 5^{\circ} 11.948^{\prime} \mathrm{E}$ & 17 Apr-26 May & RDCP 600 \\
\hline $\mathrm{C} 4$ & $61^{\circ} 18.597^{\prime} \mathrm{N}, 5^{\circ} 01.503^{\prime} \mathrm{E}$ & 18 Apr-26 May & Seaguard Current Meter 6000 \\
\hline
\end{tabular}


Table 2. Cross-tabulation of water contact $\left(W C_{i j}\right)$ between discharging sites $j$ and receiving sites $i$ for all farm sites hosting salmonid cohorts (S1-S25) in the study area. Only farm sites with a pancreas disease (PD) record are tabulated as discharging sites. The calculations are done with prevailing winds from NW $\left(5 \mathrm{~m} \mathrm{~s}^{-1}\right)$ in the particle discharge model

\begin{tabular}{|c|c|c|c|c|c|c|c|c|c|c|c|c|}
\hline \multirow{2}{*}{$\begin{array}{l}\text { Receiving } \\
\text { sites } i\end{array}$} & \multirow[b]{2}{*}{$\mathrm{S} 2$} & \multirow[b]{2}{*}{$\mathrm{S} 10$} & \multirow[b]{2}{*}{ S9 } & \multirow[b]{2}{*}{ S7 } & \multirow[b]{2}{*}{ S8 } & \multicolumn{2}{|c|}{ Discharging sites $j$} & \multirow[b]{2}{*}{$\mathrm{S} 4$} & \multirow[b]{2}{*}{ S3 } & \multirow[b]{2}{*}{$\mathrm{S} 1$} & \multirow[b]{2}{*}{$\mathrm{S} 12$} & \multirow[b]{2}{*}{ S11 } \\
\hline & & & & & & S6 & S5 & & & & & \\
\hline $\mathrm{S} 2$ & 0 & 63 & 67 & 81 & 83 & - & - & - & - & - & - & - \\
\hline S25 & 76 & 30 & 34 & 94 & - & - & - & - & - & - & - & - \\
\hline $\mathrm{S} 10$ & - & 0 & 15 & 59 & 65 & - & 86 & 83 & - & - & - & - \\
\hline S16 & - & 59 & 24 & 58 & 63 & 94 & 83 & 79 & - & - & - & - \\
\hline S9 & 99 & 99 & 0 & 50 & 57 & 86 & 74 & 70 & - & - & - & - \\
\hline S19 & 86 & - & - & - & 92 & - & 98 & - & - & - & - & - \\
\hline S22 & - & - & - & - & - & - & - & - & - & - & - & - \\
\hline $\mathrm{S} 17$ & - & - & - & - & - & - & - & - & - & - & - & - \\
\hline $\mathrm{S} 13$ & - & - & - & 80 & 64 & - & 82 & 90 & - & - & - & - \\
\hline $\mathrm{S} 23$ & - & - & - & 30 & 45 & 73 & 63 & 56 & - & 98 & - & - \\
\hline $\mathrm{S} 7$ & - & - & - & 0 & 34 & 68 & 61 & 48 & - & 82 & - & - \\
\hline S8 & - & - & - & 44 & 0 & 61 & 54 & 37 & - & 65 & - & - \\
\hline S6 & - & - & - & - & 96 & 0 & 41 & 64 & - & - & - & - \\
\hline S14 & - & - & - & - & 85 & 37 & 5 & 45 & - & 97 & - & - \\
\hline S5 & - & - & - & - & 95 & 19 & 0 & 49 & - & - & - & - \\
\hline S4 & - & - & - & - & - & 49 & 27 & 0 & - & 83 & - & - \\
\hline S3 & - & - & - & - & - & - & - & - & 0 & 59 & 67 & - \\
\hline $\mathrm{S} 1$ & - & - & - & - & - & - & - & - & - & 0 & 41 & - \\
\hline $\mathrm{S} 12$ & - & - & - & - & - & - & - & - & - & - & 0 & - \\
\hline S15 & - & - & - & - & - & - & - & - & - & - & 25 & - \\
\hline $\mathrm{S} 20$ & - & - & - & - & - & - & - & - & - & - & 57 & - \\
\hline $\mathrm{S} 21$ & - & - & - & - & - & - & - & - & - & - & 38 & - \\
\hline S11 & - & - & - & - & - & - & - & - & - & - & 73 & 0 \\
\hline $\mathrm{S} 24$ & - & - & - & 23 & 59 & 84 & 77 & 69 & - & - & - & - \\
\hline $\mathrm{S} 18$ & - & - & - & - & - & - & - & - & - & - & - & - \\
\hline
\end{tabular}

fish numbers were compiled for each month of the grow-out period. Nine of the cohorts were moved from 1 farm site to a new site during the grow-out period. All movements were between farm sites in relative proximity (Fig. 1, Table 3). For cohorts that were moved, exposure to infection pressure for consecutive months (see below) was calculated for the respective sites at which the fish were located.

Routine fish health surveillance in Norwegian salmon farming is partly the responsibility of the fish farmer, but partly there is also a mandatory system of on-site inspections by veterinarians or certified fish health biologists. For the marine sites in the present study, the requirement is 6 routine inspections $\mathrm{yr}^{-1}$ when holding $>50000$ fish, with a maximum of 3 mo between inspections. During inspections, necropsies of a representative sample of dead or moribund fish should be conducted, especially focused on detecting notifiable diseases such as PD. These regulations are enforced by the Act of 14 June 1985 no. 68 relating to aquaculture (www.ub.uio.no/cgi-bin/ujur/ulov/sok.cgi).

Records of clinical diagnosis of PD on identified sites in the study area, and the month of the diagnosis, were compiled from Kristoffersen et al. (2009). Salmonid cohorts where PD outbreaks were recorded were assigned to the case class, and cohorts where no PD outbreak was recorded were assigned to the control class. In total, $10 \mathrm{PD}$ case cohorts and 19 control cohorts were assembled. The first PD case in the area (the index PD case; S1 in Table 3) was excluded from the case class in the final analyses (see below) since this cohort by definition could not have been exposed to infection pressure by any other PD case in the study area. It is assumed that cohorts are independent units of study, although some cohorts appear successively at the same sites. There was always a period of fallowing (at least $1 \mathrm{mo}$ ) between successive cohorts at the same site (Table 3).

A detailed account of all salmonid cohort data and PD disease data (Fig. 1, Table 3) was presented to the responsible operators of the farm sites for verification of the data. Seaway distances between farm sites were compiled from Kristoffersen et al. (2009), and Euclidean distances were calculated from site coordinates.

Infection pressure. We assumed that a cohort undergoing a PD outbreak was infectious. The duration of infectivity was defined to start 2 mo prior to the month when the clinical diagnosis of PD was recorded in a given cohort, and to end when the cohort was terminated. The start definition was to take account of a time delay between the early phases of disease propagation and a subsequent PD outbreak being recorded. PD is 
Table 3. Cohorts summarised according to pancreas disease (PD) status (year and month of diagnosis), site, the start and end month at the site (i.e. the year and month the cohorts were put on the site and the year and month they were harvested), species (Sp; Atlantic salmon: $\mathrm{S}$; rainbow trout: T), the mean start and end fish weight, the maximum number (in 1000s) of fish (maxN) and mean infection pressure ( $I P$, scaled to have unit variance) based on water contact, squared sea distance (IP sea $)$ and Euclidean distance $\left(I P_{\text {euc }}\right)$. An 'IPsite' is a cohort that is not included as a case or control, but does contribute to infection pressure. The column 'Moved' denotes whether the cohort was moved from a previous site, and the number of months at this previous site is given in parentheses. By reporting the IP variant with the lowest Akaike information criterion (AIC) value (see Table 4), IP based on water contact includes biomass at infectious sites, and $I P_{\text {sea }}$ based on squared sea distances includes number of fish at infectious sites

\begin{tabular}{|c|c|c|c|c|c|c|c|c|c|c|c|c|}
\hline Site & Cohort & $\mathrm{PD}$ & Moved & $\begin{array}{c}\text { Start } \\
\text { year \& } \\
\text { month }\end{array}$ & $\begin{array}{c}\text { End } \\
\text { year \& } \\
\text { month }\end{array}$ & Sp. & $\begin{array}{l}\text { Start } \\
(\mathrm{kg})\end{array}$ & $\begin{array}{l}\text { End } \\
(\mathrm{kg})\end{array}$ & $\begin{array}{l}\operatorname{maxN} \\
(1000)\end{array}$ & $I P$ & $I P_{\text {sea }}$ & $I P_{\text {euc }}$ \\
\hline $\mathrm{S} 1$ & IPsite1 & 200508 & & 200405 & 200607 & $\mathrm{~S}$ & 0.1 & 6.1 & 492 & & & \\
\hline S3 & case1 & 200509 & & 200505 & 200612 & $\mathrm{~S}$ & 0.1 & 5.2 & 504 & 0.736 & 0.318 & 0.125 \\
\hline $\mathrm{S} 2$ & case2 & 200509 & S25 (6) & 200504 & 200607 & $\mathrm{~S}$ & 0.8 & 3.8 & 519 & 0.000 & 0.018 & 0.021 \\
\hline $\mathrm{S} 4$ & case3 & 200511 & S17 (7) & 200506 & 200605 & $\mathrm{~S}$ & 1.1 & 3.6 & 464 & 0.702 & 0.076 & 0.139 \\
\hline S5 & case4 & 200601 & & 200410 & 200607 & $\mathrm{~S}$ & 0.1 & 3.8 & 397 & 0.353 & 0.277 & 0.236 \\
\hline S6 & case5 & 200603 & & 200512 & 200611 & $\mathrm{~S}, \mathrm{~T}$ & 0.2 & 3.8 & 221 & 3.883 & 2.326 & 1.338 \\
\hline $\mathrm{S} 7$ & case6 & 200603 & & 200511 & 200610 & $\mathrm{~S}$ & 0.1 & 4.2 & 304 & 3.096 & 0.994 & 0.745 \\
\hline S8 & case 7 & 200603 & & 200510 & 200705 & $\mathrm{~S}$ & 0.1 & 4.4 & 360 & 2.203 & 0.836 & 3.701 \\
\hline S3 & case8 & 200703 & & 200610 & 200806 & $\mathrm{~S}, \mathrm{~T}$ & 0.1 & 5.2 & 643 & 0.561 & 0.052 & 0.126 \\
\hline S9 & case9 & 200706 & S10 (10) & 200607 & 200706 & $\mathrm{~S}$ & 0.7 & 4.0 & 550 & 1.266 & 0.973 & 0.328 \\
\hline $\mathrm{S} 10$ & case10 & 200707 & to $\mathrm{S} 9^{\mathrm{a}}$ & 200609 & $200707^{a}$ & $\mathrm{~S}$ & 0.1 & 0.7 & 914 & 2.361 & 1.678 & 0.439 \\
\hline $\mathrm{S} 11$ & IPsite2 & 200708 & & 200704 & & $\mathrm{~S}$ & & & & & & \\
\hline $\mathrm{S} 12$ & IPsite3 & 200804 & & 200709 & & $\mathrm{~S}$ & & & & & & \\
\hline $\mathrm{S} 13$ & cont1 & $\mathrm{N}$ & & 200405 & 200512 & $\mathrm{~T}$ & 0.1 & 5.3 & 557 & 0.143 & 0.043 & 0.053 \\
\hline S14 & cont2 & $\mathrm{N}$ & & 200405 & 200511 & $\mathrm{~S}$ & 0.1 & 5.0 & 202 & 0.317 & 0.070 & 0.195 \\
\hline S15 & cont3 & $\mathrm{N}$ & & 200410 & 200604 & $\mathrm{~S}$ & 0.1 & 3.2 & 628 & 0.000 & 0.106 & 0.135 \\
\hline $\mathrm{S} 20$ & cont4 & $\mathrm{N}$ & & 200410 & 200603 & $\mathrm{~S}$ & 0.1 & 5.0 & 319 & 0.000 & 0.131 & 0.103 \\
\hline $\mathrm{S} 11$ & cont5 & $\mathrm{N}$ & & 200504 & 200612 & $\mathrm{~S}$ & 0.1 & 5.5 & 328 & 0.000 & 0.082 & 0.204 \\
\hline S16 & cont6 & $\mathrm{N}$ & S10 (9) & 200506 & 200605 & $\mathrm{~S}$ & 0.7 & 5.2 & 463 & 1.043 & 0.357 & 0.270 \\
\hline $\mathrm{S} 17$ & cont7 & $\mathrm{N}$ & & 200509 & 200704 & $\mathrm{~S}$ & 0.1 & 4.6 & 593 & 0.000 & 0.389 & 0.349 \\
\hline $\mathrm{S} 21$ & cont8 & $\mathrm{N}$ & & 200510 & 200704 & $\mathrm{~S}$ & 0.1 & 5.8 & 290 & 0.000 & 0.071 & 0.339 \\
\hline S18 & cont9 & $\mathrm{N}$ & & 200509 & 200702 & $\mathrm{~T}$ & 0.1 & 5.1 & 194 & 0.000 & 0.254 & 0.316 \\
\hline S13 & cont10 & $\mathrm{N}$ & S22 (7) & 200603 & 200611 & $\mathrm{~T}$ & 1.1 & 3.5 & 547 & 0.388 & 0.260 & 0.307 \\
\hline S19 & cont11 & $\mathrm{N}$ & & 200605 & 200707 & $\mathrm{~S}$ & 0.2 & 4.2 & 612 & 0.320 & 0.213 & 0.360 \\
\hline $\mathrm{S} 15$ & cont12 & $\mathrm{N}$ & S12 (9) & 200607 & 200705 & $\mathrm{~S}$ & 1.1 & 6.1 & 785 & 0.000 & 0.065 & 0.438 \\
\hline $\mathrm{S} 4$ & cont13 & $\mathrm{N}$ & & 200608 & 200802 & $\mathrm{~T}$ & 0.2 & 5.9 & 955 & 0.357 & 0.428 & 0.608 \\
\hline $\mathrm{S} 20$ & cont14 & $\mathrm{N}$ & & 200610 & 200802 & $\mathrm{~S}$ & 0.1 & 5.1 & 371 & 0.000 & 0.117 & 0.454 \\
\hline $\mathrm{S} 22$ & cont15 & $\mathrm{N}$ & & 200610 & 200805 & $\mathrm{~S}$ & 0.1 & 5.7 & 275 & 0.000 & 0.164 & 0.205 \\
\hline S14 & cont16 & $\mathrm{N}$ & & 200611 & 200804 & $\mathrm{~S}$ & 0.2 & 6.1 & 328 & 0.475 & 0.362 & 0.399 \\
\hline $\mathrm{S} 23$ & cont17 & $\mathrm{N}$ & S24 (5) & 200705 & 200803 & $\mathrm{~T}$ & 0.5 & 3.9 & 239 & 1.067 & 4.986 & 1.673 \\
\hline S15 & cont18 & $\mathrm{N}$ & S12 (10) & 200707 & 200805 & $\mathrm{~S}$ & 1.3 & 5.5 & 874 & 0.143 & 0.125 & 0.645 \\
\hline S13 & cont19 & $\mathrm{N}$ & & 200704 & 200807 & $\mathrm{~S}$ & 0.1 & 4.7 & 721 & 0.115 & 0.250 & 4.300 \\
\hline
\end{tabular}

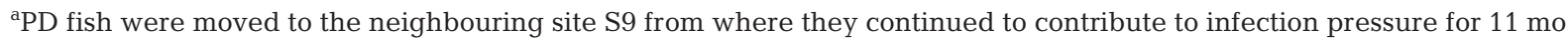

diagnosed following increased mortalities and advanced clinical symptoms. The time delay probably varies between outbreaks, but published data to evaluate this are limited. Here we fixed the time delay between the early phases of disease propagation and a subsequent PD record to 2 mo. This was partly based on re-visiting the data presented by Kristoffersen et al. (2009). These data show that the 5th percentile shortest time span from when smolts are put to sea in a PD-exposed area until PD is recorded is 3 mo. Furthermore, mortalities are reported to be induced after about 1 mo post PD infection (McLoughlin \& Graham 2007), and it may take months for SAV to spread between cages on a farm (Graham et al. 2005). Based on this information, our best guess for a fixed time delay was 2 mo. The def- inition of the end of an infective period was set to cover the whole period until an infected cohort was terminated. SAV can persist over extended periods of time ( $\geq 265 \mathrm{~d}$ post first detection in 2 Irish farms; Graham et al. 2009). The sensitivity of the definition of duration of infectivity was tested by changing the period to start 1 mo prior to the PD record and end at termination of the cohort; and to start 1 mo prior to the PD record and last 2 mo after the month of the PD record.

A susceptible cohort at a given site $i$ is assumed to be exposed to SAV infection from proximate sites at which there are infectious fish. The exposure from a given site $j$ to $i$ is inversely related to distance between the sites, or to the relative water contact $\left(W C_{i j}\right)$ between them. Furthermore, exposure from site $j$ may 
also depend on the number of fish or the biomass at the site. The sum of SAV exposures from PD outbreak sites towards a given site at a given time was termed infection pressure (ip), and was calculated for each month using Eq. (2):

$$
i p_{i}(t)=\sum_{j \in N_{P D}(t)} \frac{x_{j}(t)}{f\left(d_{i j}\right)}
$$

where $i$ is the site for which the infection pressure (ip $\left.p_{i}\right)$ is calculated in month $t_{i} N_{P D}(t)$ are all sites hosting a cohort of fish with a PD outbreak in month $t_{i} x_{j}(t)$ is defined as 1 , the maximum number of fish at site $j$ at time $t$, or the maximum biomass at site $j$ at time $t_{i} d_{i j}$ is the distance between sites $i$ and $j$, or the relative water contact $\left(W C_{i j}\right)$ between them; and $f\left(d_{i j}\right)$ is defined to be either linear, $d_{i j}$, or quadratic, $d_{i j}{ }^{2}$. The reasoning for inserting biomass or the number of fish for $x_{j}$ (in contrast to assuming $x_{j}=1$ ) was that infectiousness of an infected site was assumed to be a function of the biomass or the number of fish at this site.

To express accumulated infection pressure for cohorts, we used the mean monthly ip covering the cohort lifespan for controls, and cohort lifespan until the month of the PD record for cases. This mean infection pressure for cohorts is denoted IP. In order to check the sensitivity of accumulating the monthly ip, we tried out 3 different alternatives: mean monthly ip, maximum monthly ip and the maximum of 6 mo moving window averages of ip. Among these 3 alternatives, mean monthly ip was selected for $I P$ because the percentage of deviance explained was highest and the Akaike information criterion (AIC) value was the lowest for this alternative (results not shown).

Due to the limited number of case and control cohorts, we did not include explanatory co-variables other than $I P$ in the analyses.

Statistical analysis. Univariate logistic regression was used to evaluate the association between the probability of a PD outbreak record and the different variants of mean infection pressure:

$$
\begin{aligned}
& c_{i}=\operatorname{Bin}\left(1, p_{i}\right) \\
& \operatorname{logit}\left(p_{i}\right)=\alpha+\beta I P
\end{aligned}
$$

where $p_{i}$ is the probability of a PD outbreak record in $C_{i}$, the $i$ th cohort; $\alpha$ is the intercept term; and $\beta$ is the regression parameter for IP. AIC was used to compare the goodness of fit (variation explained) between models with different variants of $I P$.

\section{RESULTS}

Unless otherwise stated, results based on ROMS modelling refer to wind set to NW $\left(5 \mathrm{~m} \mathrm{~s}^{-1}\right)$ and particle discharge at $t_{0}$.
There was reasonable agreement between measured and modelled observations of current directions, with a tendency for measured observations to be slightly more widespread than modelled observations (Fig. 2). The highest measured current velocities, probably associated with maxima in wind speed, were not reflected in the model calculations (Fig. 3). However, for stations $\mathrm{C} 1-\mathrm{C} 3$, the modelled current velocities were generally higher than measured, whereas for station C4, modelled velocities were lower than measured (Fig. 3).

The estimates of water contact $\left(W C_{i j}\right)$ from discharging PD outbreak sites to all receiving sites hosting salmonids in the study area are given in Table 2. Characteristically, there was a pronounced asymmetry in the direction of water contact between sites. This is illustrated by site S5 from which 12 sites in northerly, westerly and easterly directions receive water, whereas S5 only receives water from 4 of these sites (S4, S6, S8 and S14). A further characteristic is that some farm sites discharge water to many other farm sites, e.g. S5, whereas some farm sites do not discharge water to any other farm sites (S3 and S11).

Changing wind from NW $\left(5 \mathrm{~m} \mathrm{~s}^{-1}\right)$ to $\mathrm{SW}\left(5 \mathrm{~m} \mathrm{~s}^{-1}\right)$, or the timing of substance discharge, generated only slight changes in the water contact matrix. Most importantly, the pairwise sites showing water contact were consistent between the 3 variants of the water contact matrices. Average maximum differences of $W C_{i j}$ (absolute values) for each discharging site $j$ were 8 and 10 when wind direction and timing of substance discharge were changed, respectively.

PD was diagnosed in 13 salmonid cohorts in the study area during the period January 2005 to July 2008. The timing of the PD diagnosis varied between 4 and 16 mo post stocking on given sites (Table 3). Excluding the index PD case, as well as 2 cohorts that had not been terminated prior to August 2008, there remained $10 \mathrm{PD}$ cohorts (cases) and 19 cohorts for which PD was not detected (controls). Three of the PD cohorts as well as 5 of the control cohorts were moved from 1 site to a second site during the marine grow-out period (Table 3).

\section{Infection pressure (IP)}

When $I P$ was estimated on the basis of water contact, only 1 out of 10 PD case cohorts was not exposed to IP. For control cohorts, 9 out of 19 were not exposed to IP (Table 3). The 2 case cohorts (cases 5 and 6) on the neighbouring sites S6 and S7 were exposed to the highest mean infection pressure of all cohorts (Table 3). When $I P$ was estimated on the basis of Euclidean or seaway distances, all cohorts were by definition 

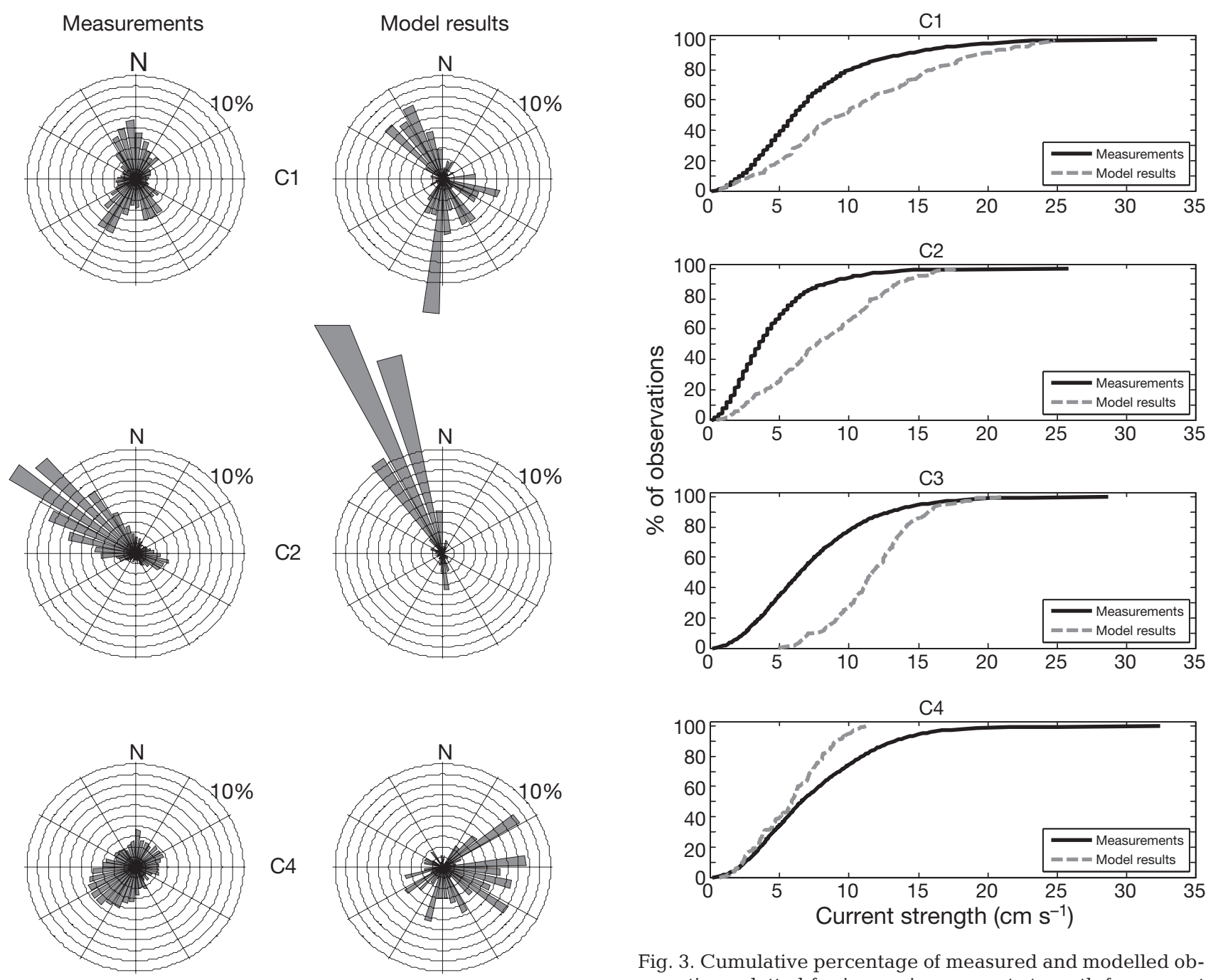

Fig. 3. Cumulative percentage of measured and modelled observations plotted for increasing current strength for current measurement Stns C1-C4
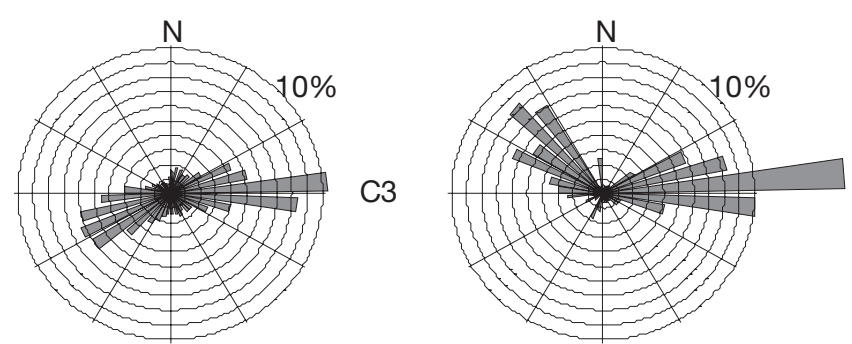

Fig. 2. Radial frequency diagrams showing the percentage of measured (left) and modelled (right) current directions for current measurement Stns $\mathrm{C} 1-\mathrm{C} 4$. The outer ring represents

$10 \%$ of measurements/calculations

exposed to IP (Table 3). The control cohort consisting of rainbow trout (cont 17) that was moved after 5 mo from S24 to S23 was exposed to high IP irrespective of the basis for estimation, but especially high for IP based on squared seaway distance (Table 3).

\section{Logistic regression}

The logistic regression model (Eq. 3) was fitted to variants of $I P$. For $I P$ based on water contact, the probability of a cohort ending with a recorded PD outbreak increased significantly with increasing $I P(p=0.02$, Table 4, Fig. 4).

For variants of $I P$ based on Euclidean or seaway distance, there was no linear association between logit of the probability of a PD outbreak and IP. A generalised additive model (GAM) allowing for non-linear relationships for $I P$ (with a maximum of $2 \mathrm{df}$ for the spline function; Hastie \& Tibshirani 1990) improved the data fit. This yielded a significant positive (non-linear) relationship between the logit of the probability of a cohort ending with a recorded PD outbreak and IP based on numbers of fish and squared sea distance $(p=0.05$, Table 4). 
Table 4. p-values of mean infection pressure $(I P)$, percentage of deviance explained (Dev exp, \%) and Akaike information criterion (AIC) values of the model variants. In cases where a non-linear model (maximum of $2 \mathrm{df}$ for the smooth spline) gave a better fit than the linear logistic regression model, this is shown by EDF > 1. EDF: estimated effective degrees of freedom for the spline function in a generalised additive model (GAM). D: distance; \#: maximum number of fish; Bio: maximum biomass in $I P$ contributing cohorts

\begin{tabular}{|lcccc|}
\hline$I P$ & $\mathrm{p}$ & $\mathrm{AIC}$ & Dev exp (\%) & EDF \\
\hline Water contact & 0.01 & $\mathbf{3 0 . 5}$ & 29.0 & 1 \\
Sea D & 0.33 & 40.3 & 4.5 & 1.3 \\
Sea D & 0.08 & 37.0 & 16.1 & 1.8 \\
Euclidean $^{2}$ & 0.75 & 41.2 & 0.3 & 1 \\
Euclidean $^{2}$ & 0.89 & 41.3 & 0.1 & 1 \\
\# \& water contact & 0.02 & $\mathbf{2 9 . 6}$ & 31.4 & 1 \\
Bio \& water contact & 0.02 & $\mathbf{2 7 . 4}$ & 37.3 & 1 \\
\# \& sea D & 0.05 & 33.8 & 25.0 & 1.9 \\
Bio \& sea D & 0.08 & 34.0 & 24.2 & 1.9 \\
\hline
\end{tabular}
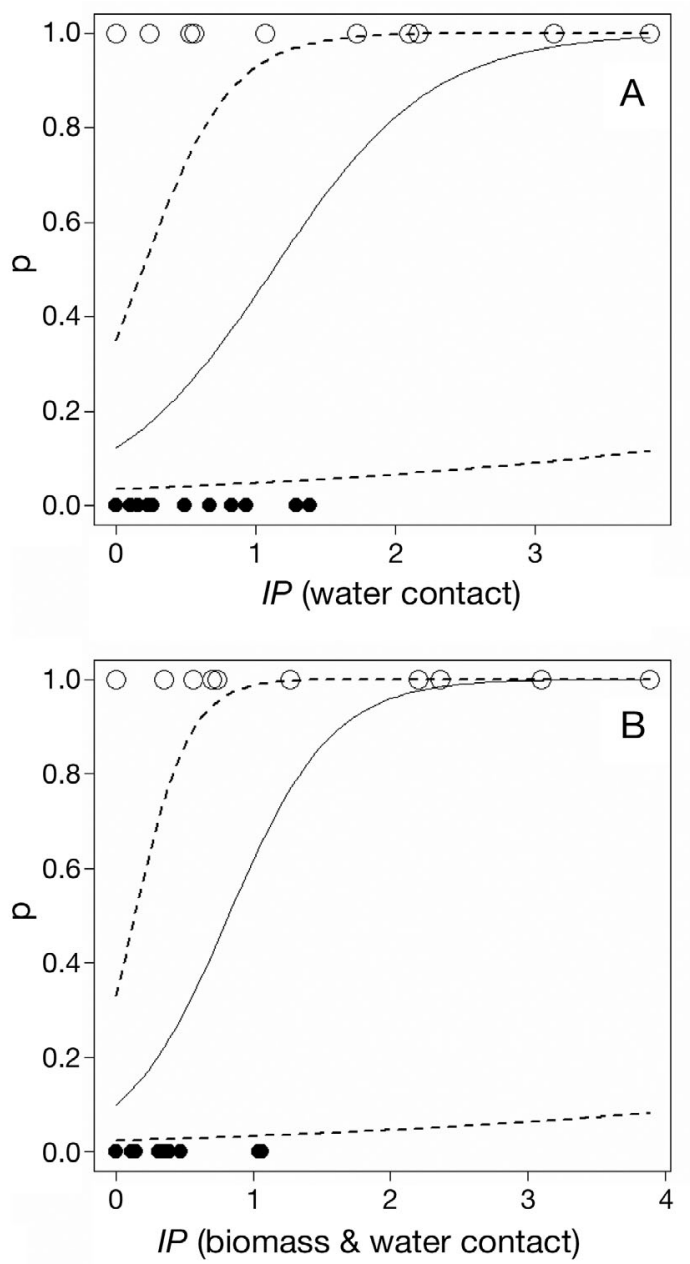

Fig. 4. Estimated probability (line $\pm 95 \% \mathrm{CI}$; dashed lines) of a PD outbreak in a cohort as a function of mean infection pressure $(I P)$ estimated on the basis of $(\mathrm{A})$ water contact, and (B) water contact and biomass. IP of case (O) and control cohorts $(\bullet)$ are indicated
We ranked the models according to their AIC value (Table 4). The models best predicting PD cases versus controls were those with IP based on water contact. Among these, the version including biomass on infected farm sites showed the highest amount of deviance explained (37\%) and a lower AIC. The nonlinear models for which infection pressure was based on squared sea distance did better than both Euclidean distance and non-transformed sea distance, but were inferior to the models based on water contact (Table 4).

\section{Sensitivity}

Above we assumed that a cohort with a PD outbreak is infectious from 2 mo before PD is recorded and until the cohort is terminated. By reducing the infectious period prior to a PD record to only $1 \mathrm{mo}$, the rank of the models remained the same and the AIC values increased only slightly (max. difference in $\mathrm{AIC}=1.8$, cf. Table 4). When further restricting the infectious period to start 1 mo prior to the PD record and end 2 mo after the record, the overall results were the same and the best model was still the one with IP based on biomass at the infectious sites and water contact (AIC $=30.4)$. The linear relationship between the logit of the probability of a cohort ending with a recorded PD outbreak and IP was significant $(p=0.03)$, and there was an AIC difference of 2.8 to the best model with IP based on squared seaway distance.

To test the sensitivity of altering wind direction and the timing of the substance discharge, the water contact matrix used to estimate $I P$ was substituted by the alternative matrices: wind $\operatorname{SW}\left(5 \mathrm{~m} \mathrm{~s}^{-1}\right)$ direction or timing of the substance discharge from $t_{6}(\mathrm{~h})$. This did not significantly alter the results. The numbers of exposed and unexposed case and controls were exactly the same under the different scenarios. Compared to the original water contact matrix, AIC values for logistic regression models of IP based on the variants of water contact (see Table 3) did not differ by more than 1 unit if estimated by using any of the alternative matrices of water contact.

When accumulating infection pressure, there is a potential bias between cohorts exposed late versus early in their production cycle. However, alternative ways of accumulating infection pressure (maximum monthly ip or maximum of 6 mo moving window averages of ip) all selected the logistic regression model with IP based on water contact and biomass on infected sites as the best one (smallest AIC value; results not shown). This may suggest that the results are not very sensitive to the potential bias in $I P$. 


\section{DISCUSSION}

This study presents a simple statistical model that accounts for the effect of exposure to SAV infection from proximate fish farms with PD on the probability of acquiring PD in farmed salmonids. Exposure to infection as expressed by infection pressure using water contact between farm sites showed to be the best predictor of PD cases and controls in the model. Infection pressure based on water contact performed significantly better than seaway distances, which in turn performed significantly better than Euclidean distances. Since the spread of PD in the study area was best explained by modelled water velocity, we conclude that the study supports the hypothesis that PD is spread between fish farms by passive drift of the infectious agent SAV in the water current.

We are only aware of one earlier study that has shown an effect of current velocity on the spread of aquatic diseases, which was a study on the spread of ISA in the USA and Canada (Gustafson et al. 2007). However, many studies have addressed the local horizontal spread of aquatic diseases and have suggested that passive drift of infectious agents is a plausible explanation (e.g. Jarp \& Karlsen 1997, Fringuelli et al. 2008, Kristoffersen et al. 2009). One difficulty in showing that water currents play a role in spreading diseases is the timeframe of events relating to hydrodynamics versus disease dynamics. The aquatic environment is a highly dynamic system where current velocities are constantly influenced by winds, tides, freshwater inflow and other factors. This implies that forecasting movement of water by modelling becomes increasingly uncertain with time. The hydrodynamic model was run for $1 \mathrm{wk}$ for the estimation of water contact between farm sites. This was then used to model the spread of a disease where the limited information available is the point in time where an outbreak is recorded in a cohort of fish. It is not known when the actual infection event on a given site happened, but the time between event and record is likely to vary between outbreaks. It is also unknown how the disease propagates in infected cohorts, and how this varies between cohorts. Disease propagation probably affects infectivity over time, and hence local infection pressure. The present solution to overcome the apparent mismatch in timescales for the hydrodynamic processes compared to the disease processes is that we assume that the water contact matrix (Table 2) is generally valid over time. The sensitivity of this assumption was partly tested by changing the wind conditions in the model, by changing the timing of discharge of the modelled particles, and by validating the model through measurements of stream velocities. Reasonable agreement between measured and modelled observations of currents, as well as relatively small ef- fects of changing wind conditions and discharge timing in the ROMS model, suggest that the water contact matrix is generally valid over time. We interpret the agreement between measured and modelled observations of currents as an indication that the tides dominate the current conditions in the area, and let this justify the fact that limited effort was put in analysing wind effects. Winds obviously also influence the currents (Amundrud \& Murray 2009). Nevertheless, a possible explanation for why the tides seem to dominate current conditions and the spread of SAV infection between farm sites may be related to the timescales involved. A typical timescale for spreading infections between sites is on the order of days. Wind direction typically varies from 0 to $360^{\circ}$ during $1 \mathrm{~d}$ in the study area. Long-lasting winds from 1 direction are rare, so in a time span of $1 \mathrm{wk}$, wind effects are averaged out and the predictable tidal current pattern dominates.

With respect to the disease dynamics, it was recently shown on a large scale that the most important predictor of PD outbreaks in salmonid cohorts in Norway was neighbourhood infectious status as expressed by infection pressure (Kristoffersen et al. 2009). This study along with the study of Graham et al. (2007), suggests that SAV is contagious and sufficiently viable in the aquatic environment to be a good candidate for testing possible effects of water currents on the spread of PD on a local scale.

One important contribution from this study is the tabulation of relative water contacts between farm sites in the study area (Table 2). This table is potentially useful in risk assessments aimed at controlling and preventing disease emergencies (Murray 2008). For example, it may be used by the operators of the farm sites as a basis for developing an early warning system with respect to infectious diseases in the area. An operator of a given farm site should then pay special attention to upstream farm sites in water contact. Obviously, such a system applies only to infections that transmit by passive drift in the water current, such as suggested for the viral diseases ISA (Gustafson et al. 2007) and PD (present study). It must be emphasised, however, that the present ROMS modelling that generated Table 2 was done with limited settings for the driving forces for the hydrodynamics. Altering these settings may alter the quantities of relative water contact between sites, and there is a need for further exploration of the sensitivity of ROMS to varying environmental conditions. Nevertheless, the present increased predictability of PD outbreaks using water contact compared to physical distances recommends knowledge on hydrodynamics as the basis for assessing risks of local disease spread.

There are 2 noticeable features of the estimated water contact matrix. First, the number of receiving 
farm sites for the discharging farm sites was relatively variable. Farm sites that discharge water to many other farm sites may play a key role in spreading diseases locally. Second, there was a pronounced asymmetry in contact direction such that farm sites discharging water to a given farm site are not the same as those which receive water from the given farm site. This is because current directions are not evenly distributed, which is clearly illustrated in Fig. 2. Both of these features are worth considering when assessing risks of local disease spread. It may, for example, be recommended that hydrodynamic modelling should be used to assess locations of new sites for fish farming with regard to water contacts with neighbouring farm sites.

Exact knowledge on how diseases spread is essential for designing targeted control measures. By using hydrodynamics to explain the spread of PD, we disentangled 1 specific transmission pathway for SAV, viz. transmission by passive drift, from many potential pathways that may operate locally (see Kristoffersen et al. 2009). Along with having shown that water currents spread PD, although for a restricted dataset, the water contact relationships can be used to predict the spread of PD locally. Hence, knowledge on local water contact relationships will allow risk-based surveillance and targeted control measures for diseases that spread by passive drift.

Acknowledgements. We are grateful for cooperation and finances given by the fish farming companies Steinvik Fiskefarm, Marine Harvest Norway Region West, Marø Havbruk, E. Karstensen Fiskeoppdrett, Karma Havbruk, Slakteriet, Flokenes Fiskefarm, Havlandet Havbruk, Firda Sjøfarmed and Nærøysund Matfisk. We are also grateful for the assistance by the Directorate of Fisheries, Region West, by F. Hovland and The Norwegian Food Safety Authority, District of Sunnfjord and Ytre Sogn by T. Lysne and H. Øgaard. D. A. Graham commented on a draft of the manuscript and A. B. Kristoffersen provided parts of the data for the study. The reported work was partly financed by the county of Sogn and Fjordane through project no 06/2161-28 Aqua Strøm.

\section{LITERATURE CITED}

Amundrud TL, Murray AG (2009) Modelling sea lice dispersion under varying environmental forcing in a Scottish sea loch. J Fish Dis 32:27-44

Fringuelli E, Rowley HM, Wilson JC, Hunter R, Rodger H, Graham DA (2008) Phylogenetic analyses and molecular epidemiology of European salmonid alphaviruses (SAV) based on partial E2 and nsP3 gene nucleotide sequences. J Fish Dis 31:811-823

Graham DA, Jewhurst VA, Rowley HM, McLoughlin MF, Rodger H, Todd D (2005) Longitudinal serological surveys of Atlantic salmon Salmo salar L., using a rapid immunoperoxidase-based neutralization assay for salmonid alphavirus. J Fish Dis 28:373-379
Graham DA, Staples C, Wilson CJ, Jewhurst H, Cherry K, Gordon A, Rowley HM (2007) Biophysical properties of salmonid alphaviruses: influence of temperature and $\mathrm{pH}$ on virus survival. J Fish Dis 30:533-543

Graham DA, Fringuelli E, Wilson C Rowley HM and others (2009) Prospective longitudinal studies of salmonid alphavirus on two Atlantic salmon farms in Ireland; evidence for viral persistence. J Fish Dis in press doi: 10.1111/j.1365-2761.2009.01096.x

Gustafson LL, Ellis SK, Beattie MJ, Chang BD and others (2007) Hydrographics and the timing of infectious salmon anemia outbreaks among Atlantic salmon (Salmo salar L.) farms in the Quoddy region of Maine, USA and New Brunswick, Canada. Prev Vet Med 78:35-56

Haidvogel DB, Arango H, Budgell WP, Cornuelle BD and others (2008) Ocean forecasting in terrain-following coordinates: formulation and skill assessment of the Regional Ocean Modeling System. J Comput Phys 227:3595-3624

Hastie TJ, Tibshirani RJ (1990) Generalized additive models. Chapman \& Hall, London

Jarp J, Karlsen E (1997) Infectious salmon anaemia (ISA) risk factors in sea-cultured Atlantic salmon Salmo salar. Dis Aquat Org 28:79-86

Kristoffersen AB, Viljugrein H, Kongtorp RT, Brun E, Jansen PA (2009) Risk factors for pancreas disease (PD) outbreaks in farmed Atlantic salmon and rainbow trout in Norway during 2003-2007. Prev Vet Med 90:127-136

McLoughlin MF, Graham DA (2007) Alphavirus infections in salmonids - a review. J Fish Dis 30:511-531

Murray AG (2008) Existing and potential use of models in the control and prevention of disease emergencies affecting aquatic animals. Rev Sci Tech Off Int Epizoot 27:211-228

Murray AG, Amundrud TL, Gillibrand PA (2005) Models of hydrodynamic pathogen dispersal affecting Scottish salmon production: modelling shows how Scotland eradicated ISA, but not IPN. Bull Aquacult Assoc Can 105: $79-86$

> Petterson E, Sandberg M, Santi N (2009) Salmonid alphavirus associated with Lepeophtheirus salmonis (Copepoda: Caligidae) from Atlantic salmon, Salmo salar L. J Fish Dis 32:477-479

> Rodger H, Mitchell S (2007) Epidemiological observations of pancreas disease of farmed Atlantic salmon Salmo salar L., in Ireland. J Fish Dis 30:157-168

Staalstrøm A (2009) Validering av havmodellen i AquaStrøm prosjektet. NIVA report no. 5842-2009. Norwegian Institute of Water Research, Oslo

Stagg RM (2003) The eradication of an outbreak of clinical infectious salmon anaemia from Scotland. In: Miller O, Cipriano RC (eds) International response to infectious salmon anemia: prevention control, and eradication: Proc Symp 3-4 Sept 2002, New Orleans, LA. Tech Bull No 1902. US Dept Agric, Anim Plant Health Inspect Serv, US Dept Interior, US Geol Surv, US Dept Commerce, Natl Mar Fish Serv, Washington, DC, p 111-124

Stucchi DJ, Henry RF, Foreman GG (2005) Modelling the transport and dispersion of IHN pathogens in the Broughton Archipelago, British Columbia. Bull Aquacult Assoc Can 105:52-59

> Weston JH, Welsh MD, McLoughlin MF, Todd D (1999) Salmon pancreas disease virus, an alphavirus infecting farmed Atlantic salmon, Salmo salar L. Virology 256: 188-195

Submitted: June 18, 2009; Accepted: September 21, 2009

Proofs received from author(s): December 17, 2009
Editorial responsibility: Julie Bebak,

Auburn, Alabama, USA 